\title{
Disease activity, morning stiffness and missing teeth are associated with oral health-related quality of life in individuals with rheumatoid arthritis
}

\author{
Gerhard Schmalz ${ }^{1} \cdot$ Stefan Noack $^{1} \cdot$ Susann Patschan ${ }^{2} \cdot$ Daniel Patschan $^{2} \cdot$ Gerhard A. Müller $^{3} \cdot$ Annegret Rupprecht $^{1}$. \\ Jan Schmickler ${ }^{1} \cdot$ Rainer Haak $^{1} \cdot$ Dirk Ziebolz $^{1}$ (i)
}

Received: 4 November 2019 / Accepted: 23 January 2020 / Published online: 6 February 2020

(C) The Author(s) 2020

\begin{abstract}
Objectives The aim of this cross-sectional study was to assess oral health-related quality of life (OHRQoL) in patients with rheumatoid arthritis (RA) and its relation to specific RA characteristics.

Material and methods Within the oral examination, the need for dental (carious teeth showing cavitation) and periodontal treatment (presence of a probing depth $\geq 3.5 \mathrm{~mm}$ ) and the number of missing teeth $(\mathrm{M}-\mathrm{T}$ ) were recorded. OHRQoL was assessed with the German short version of the Oral Health Impact Profile (OHIP G14). The disease activity score (DAS28-ESR), disease duration, number of swollen/painful joints and duration of morning stiffness were retrieved from the patient records.

Results A total of 176 patients with a mean age of $62.5 \pm 10.2$ years were included. The overall OHIP G14 sum score was $5.4 \pm$ 7.1. The M-T showed a significant correlation with the dimensions of oral function $(r=0.25, p=0.001)$ and psychosocial impact $(r=0.20, p=0.009)$ and the sum score $(r=0.26, p=0.001)$. The DAS28-ESR showed a significant correlation with psychosocial impact $(r=0.19, p=0.012)$ and the sum score $(r=0.16, p=0.041)$. The duration of morning stiffness was correlated with oral function $(r=0.19, p=0.019)$, psychosocial impact $(r=0.18, p=0.024)$ and the sum score $(r=0.22, p=0.006)$. The effect size of these correlations was interpreted as small.

Conclusion Disease activity, morning stiffness and missing teeth are associated to OHRQoL of patients with RA. Accordingly, multidisciplinary dental care appears necessary for these patients.

Clinical relevance The prevention of tooth loss as well as the consideration of psychosocial and disease-specific parameters in the multidisciplinary dental care of RA patients is necessary.
\end{abstract}

Keywords Rheumatoid arthritis · Oral health · Quality of life · Dental care

Gerhard Schmalz and Stefan Noack contributed equally as the first author.

Dirk Ziebolz

dirk.ziebolz@medizin.uni-leipzig.de

1 Deptartment of Cariology, Endodontology and Periodontology, University of Leipzig, Liebigstr. 12, D 04103 Leipzig, Germany

2 Department of Cardiology, Angiology and Nephrology, Klinikum Brandenburg, Medizinische Hochschule Brandenburg, Neuruppin, Brandenburg, Germany

3 Department of Nephrology and Rheumatology, University Medical Centre Goettingen, Goettingen, Germany

\section{Introduction}

The main objectives in the therapy of rheumatoid arthritis (RA) are to manage inflammation-related pain and to maintain or improve physical function, as well as the quality of life, of patients [1]. This is because patients suffering from RA show distinct changes in their quality of life that are caused not only by direct effects of the underlying disease but also by different psychological factors [2]. Accordingly, a reduced quality of life and a high prevalence of anxiety and depression can be observed in RA patients [3].

Oral health-related quality of life (OHRQoL) is a specific sub-aspect of general health-related quality of life that can be affected by both oral and general health [4]. In general, dental and periodontal disease negatively influence OHRQoL [5, 6]; however, an influence of general health and disease burden on 
OHRQoL, especially in medically compromised patients, e.g. patients undergoing haemodialysis or suffering from ankylosing spondylitis, has previously been reported [7, 8]. Accordingly, several previous studies have evaluated the OHRQoL of patients with RA, showing reduced OHRQoL in these individuals in comparison to generally healthy individuals [9-12]. Different explanations might be conceivable for the worse OHRQoL in RA patients: on the one hand, it is well known that RA is associated with periodontitis [13-15]. Furthermore, patients with RA were found to show an increased number of missing teeth [14-16]. Moreover, disease- or medication-related complaints such as xerostomia can reduce OHRQoL in patients suffering from RA [17]. In contrast, a recent study showed the impaired OHRQoL to be independent of the oral health condition [9]. Another study was able to show associations between disease-specific parameters and OHRQoL in a cohort of patients with ankylosing spondylitis [8]. These findings make an influence of RAspecific parameters on OHRQoL in RA patients conceivable. Until now, this has been only an assumption and has not yet been confirmed by clinical examinations.

Accordingly, the current study aimed to assess OHRQoL in a large cohort of patients with RA. To draw conclusions about the main reason for the reduced OHRQoL, an analysis of the different dimensions "oral function", "psychosocial impact", "oral pain" and "orofacial appearance" should be executed. Therefore, associations of oral health as well as specific RA characteristics with OHRQoL and the different dimensions should be investigated. It was hypothesized that diseasespecific factors are associated with the psychosocial impact dimension of OHRQoL.

\section{Materials and methods}

\section{Design}

The current investigation was designed as a clinical, monocentric, cross-sectional study. It has been reviewed and approved by the local ethics committee (application No. 14/2/ 13). All included participants were informed verbally and in writing about the rationale and course of the study and gave their written informed consent for participation.

\section{Study participants}

During the routine examination, patients suffering from RA were informed about the study and asked for their voluntary participation. For the current study, patients were selected on the basis of previously defined in- and exclusion criteria. An age of at least 18 years and a medical diagnosis of RA according to the criteria of the American College of Rheumatology and the European League Against Rheumatism [18] assessed by a rheumatologist were the mandatory conditions for participation. Furthermore, the following exclusion criteria were used: severe general disorders preventing the individual from undergoing oral examinations, immunosuppressive therapy other than RA medication, infectious diseases, addictive disorders, diabetes mellitus, cardiovascular diseases, neuropathy, pregnancy and renal disorders.

From the general health records in the rheumatology clinic, the age, sex, smoking habits (smoker or not), disease duration (time since first RA diagnosis), current disease activity score for RA (DAS28-ESR) [19], the presence of swollen or painful joints and morning stiffness of the participants were assessed.

\section{Patient questionnaires}

\section{Oral health behaviour}

All participants were asked to answer specific questions regarding their oral health behaviour, including the subjective importance of healthy teeth for themselves, the self-reported history of dental rehabilitation since they received an RA diagnosis, the time since their last dental visit and the reason for their last dental visit.

\section{Oral health impact profile (OHIP G14)}

All participants had to fill out the German short version of the Oral Health Impact Profile (OHIP G14), which is a valid instrument for assessing OHRQoL [20, 21]. Therefore, the occurrence of 14 functional and psychosocial impacts that participants experienced in the previous month as a result of complaints with their teeth, mouth or dentures was assessed. For each question, there were five different answer options: very often $=$ " 4 ", fairly often $=$ " 3 ", occasionally = "2", hardly ever $=$ " 1 " and never $=$ " 0 ". Accordingly, a total score between " 0 " (all questions were answered with "never") and " 56 " (all questions were answered with "very often") was possible. Aside from statistical significance, differences in OHIP G14 values by an average of 2 or more points were interpreted as clinically relevant, following the principle of minimally important difference [22]. In addition to the sum score of the OHIP G14, the four different dimensions, "oral function", "psychosocial impact", "oral pain" and "orofacial appearance", were considered [23]. Furthermore, the dimensions "disability and handicap", "pain" and "limitation and discomfort" are presented [24].

\section{Oral examination}

All patients underwent one oral examination under standardized conditions, which was conducted by two experienced and calibrated dentists (kappa $\geq 0.8$ ). Within the oral examination, the need for dental and periodontal treatment was determined. 
The dental examination included the visual evaluation of the number of decayed (D-T), missing (M-T) and filled teeth (F-T) (DMF-T index) [25] with a mirror and probe. Thus, teeth with a carious cavitation on the tooth surface indicated the need for dental treatment and were assigned to the D-T component. The presence of a D-T of $\geq 1$ was interpreted as "dental treatment need". To assess periodontal treatment need, the periodontal probing depth (PD) and bleeding on probing (BOP) were assessed at 6 measurement points per tooth using a periodontal probe with a millimetre scale (PCP 15; Hu Friedy, Chicago, IL, USA). According to PSR/PSI [26], a PD of $\geq 3.5 \mathrm{~mm}$ in more than one sextant was interpreted as a need for periodontal treatment.

\section{Statistical analysis}

Statistical analysis was performed using SPSS, Version 23.0 (SPSS Inc., USA.). Metric variables are presented as the mean values and standard deviations. Categorical data are presented as absolute and relative frequencies. To compare the two independent samples, the Mann-Whitney U test was applied; more than two independent variables were analysed using the Kruskal-Wallis test. To detect correlations between the OHIP G14 values and specific parameters, Spearman's rank correlation coefficient was applied. According to Cohen 1988, the effect size of correlations was interpreted as small $(0.1-$ $0.3)$, medium $(0.3-0.5)$ or large $(>0.5)$ [27]. The significance level was set at $p<0.05$.

\section{Results}

\section{Patients}

A total of 176 patients with a mean age of $62.5 \pm 10.2$ years were included. All participants suffered from RA, with an average disease duration of $92.0 \pm 102.0$ months and a disease activity score (DAS28-ESR) of $3.6 \pm 1.4$. The periodontal treatment need was very high, as it was present in $97 \%$ of the patients (Table 1).

\section{OHIP G14 findings}

The mean overall OHIP G14 sum score was $5.4 \pm 7.1$. The values corresponding to the different dimensions and the included single questions are presented in Table 2 .

Because of the high prevalence of periodontal treatment need $(97 \%)$, the association of this parameter with the OHIP G14 values could not be analysed. While dental treatment need showed no associations with the OHIP findings, the M$\mathrm{T}$ showed a significant correlation with the dimensions of oral function $(r=0.25, p=0.001)$ and psychosocial impact $(r=$ $0.20, p=0.009)$ as well as the OHIP G14 sum score $(r=0.26$,
Table 1 Characteristics of the participants in the RA group

\begin{tabular}{ll}
\hline Parameter & Patients $(n=176)$ \\
\hline Gender (male) [n (\%)] & $32 / 176(18 \%)$ \\
Age in years (mv $\pm \mathrm{SD})$ & $62.5 \pm 10.2$ \\
Smoker [n (\%)] & $40(23 \%)$ \\
Disease duration in months $(\mathrm{mv} \pm \mathrm{SD})$ & $92.0 \pm 102.0$ \\
DAS28-ESR (mv $\pm \mathrm{SD})$ & $3.6 \pm 1.4$ \\
Number of swollen joints $(\mathrm{mv} \pm \mathrm{SD})$ & $3.1 \pm 3.9$ \\
Number of painful joints $(\mathrm{mv} \pm \mathrm{SD})$ & $6.5 \pm 6.8$ \\
Morning stiffness in min $(\mathrm{mv} \pm \mathrm{SD})$ & $38.4 \pm 47.0$ \\
Number of missing teeth $(\mathrm{M}-\mathrm{T})(\mathrm{mv} \pm \mathrm{SD})$ & $6.2 \pm 5.6$ \\
Dental treatment need $[\mathrm{n}(\%)]$ & $34(19 \%)$ \\
Periodontal treatment need $[\mathrm{n}(\%)]$ & $171(97 \%)$ \\
\hline
\end{tabular}

$n$ number of patients, $m v$ mean value, $s d$ standard deviation, DAS28-ESR disease activity score

Table 2 Results for the different dimensions of the OHIP G14 and included questions as well as the sum score

\begin{tabular}{|c|c|c|c|c|c|c|}
\hline \multirow[t]{2}{*}{ OHIP G14 dimensions/questions } & \multicolumn{6}{|c|}{ RA group } \\
\hline & 0 & 1 & 2 & 3 & 4 & Total \\
\hline \multicolumn{7}{|l|}{ Oral function } \\
\hline Total oral function & - & & & & & $2.0 \pm 2.8[0]$ \\
\hline Trouble pronouncing words & 161 & 6 & 6 & 3 & 0 & $0.2 \pm 0.6[0]$ \\
\hline Sense of taste worsened & 144 & 7 & 16 & 5 & 4 & $0.4 \pm 0.9[0]$ \\
\hline Interrupt meals & 151 & 6 & 15 & 4 & 0 & $0.3 \pm 0.7[0]$ \\
\hline Uncomfortable eating & 107 & 16 & 32 & 19 & 2 & $0.8 \pm 1.1[0]$ \\
\hline Diet unsatisfactory & 141 & 19 & 14 & 2 & 0 & $0.3 \pm 0.7[0]$ \\
\hline \multicolumn{7}{|l|}{ Psychosocial impact } \\
\hline Total psychosocial impact & - & & & & & $2.4 \pm 4.0[0]$ \\
\hline Life less satisfying & 133 & 13 & 20 & 7 & 3 & $0.5 \pm 1.0[0]$ \\
\hline Difficulty relaxing & 129 & 9 & 27 & 6 & 5 & $0.6 \pm 1.1[0]$ \\
\hline Felt tense & 131 & 9 & 24 & 9 & 3 & $0.6 \pm 1.0[0]$ \\
\hline Irritable with other people & 160 & 6 & 7 & 3 & 0 & $0.2 \pm 0.6[0]$ \\
\hline Difficulty doing usual jobs & 160 & 5 & 7 & 4 & 0 & $0.2 \pm 0.6[0]$ \\
\hline Unable to function & 163 & 8 & 3 & 2 & 0 & $0.1 \pm 0.5[0]$ \\
\hline Been embarrassed & 145 & 10 & 14 & 6 & 1 & $0.3 \pm 0.8[0]$ \\
\hline \multicolumn{7}{|l|}{ Oral pain } \\
\hline Painful aching in mouth & 119 & 14 & 27 & 14 & 2 & $0.7 \pm 1.1[0]$ \\
\hline \multicolumn{7}{|l|}{ Orofacial appearance } \\
\hline Felt self-conscious & 145 & 10 & 14 & 5 & 2 & $0.4 \pm 0.8[0]$ \\
\hline \multicolumn{7}{|l|}{ OHIP G14 sum score } \\
\hline Sum score & - & & & & & $5.4 \pm 7.1[2.5]$ \\
\hline \multicolumn{7}{|l|}{ Further dimensions } \\
\hline Disability and handicap & - & & & & & $2.1 \pm 3.6[0]$ \\
\hline Pain & - & & & & & $1.5 \pm 1.9[0]$ \\
\hline Limitation and Discomfort & - & & & & & $1.8 \pm 2.7[0]$ \\
\hline
\end{tabular}

Values are shown as the mean value \pm standard deviation [median] 
$p=0.001$; Fig. 1a-c). The participants who rated the importance of oral health for themselves as high had a clinically relevant higher OHIP G14 sum score than those who provided lower ratings $(5.9 \pm 7.5$ vs. $3.8 \pm 5.6 ; p=0.061$; Table 3$)$. Furthermore, the time since the last dental visit $(p=0.024)$ and reason for visiting the dentist $(p=0.036)$ showed clinically relevant and statistically significant associations with the dimension psychosocial impact (Table 3).

\section{Correlations of OHIP with age and disease-specific parameters}

The dimension psychosocial impact showed a negative correlation with the age of the patients $(r=-0.19, p=0.012)$. The DAS28-ESR of the participants showed a significant correlation with the dimension psychosocial function $(r=0.19, p=$ $0.012)$ and the OHIP G14 sum score $(r=0.16, p=0.041$; Table 4). Furthermore, the duration of morning stiffness was found to be correlated with the dimensions of oral function $(r=0.19, p=0.019)$ and psychosocial impact $(r=0.18, p=$ $0.024)$ as well as with the OHIP G14 sum score $(r=0.22, p=$ 0.006; Table 4).

\section{Discussion}

Summary of the main results: In particular, the number of missing teeth was found to be correlated with the OHIP G14 sum score and the dimensions oral function and psychosocial impact. Furthermore, disease activity assessed by the DAS28ESR and duration of morning stiffness showed correlations with the OHIP G14 findings. Thus, disease activity was correlated with the sum score and dimension psychosocial impact, while morning stiffness showed a correlation to all of the above, the sum score, oral function and psychosocial impact.
Comparison with international literature: Within the current study, no healthy control group was recruited. However, the available reference values for the healthy general population allow for a close comparison of the OHIP G14 sum score. These reference values have been provided by John et al. and indicate a median score of 0 for dentate patients and $\leq 4$ for partially dentate patients [28]. As the current study included both fully and partially dentate participants, a median value between 0 and 4 in the OHIP G14 sum score can be interpreted as comparable to the generally healthy population. Although the mean value of the sum score was $5.4 \pm 7.1$ and was thus slightly higher than the reference values, the median value for the RA patients in the current study was 2.5 . This result suggests that the OHRQoL of the total cohort is not considerably worse than that in the healthy general population. A previous study examined a cohort of 100 patients suffering from RA regarding their OHRQoL and found a mean value of 7.3 for the OHIP sum score, which is slightly higher than that in the current study [9]. Similarly, the OHIP results for patients with ankylosing spondylitis, a more severe rheumatic disease, indicated a mean value of 6.2 , which is comparable to the current study's findings [8]. Moreover, a large Finnish evaluation that administered the OHIP14 to RA patients showed slightly higher OHIP scores than the current study as well [12]. Another recent study found a moderate reduction in OHRQoL in RA-affected subjects [10]. Only Blaziot et al. concluded that the OHRQoL of patients with RA is poor [11]. Accordingly, the literature suggests a slight to moderate reduction in OHRQoL in patients suffering from RA, which can be supported by the findings of the current study.

To understand the complexity of OHRQoL, the analysis of its four dimensions, including "oral function", "psychosocial impact", "orofacial appearance" and "oral pain", can be recommended [23]. This might identify which dimension is mainly affected in RA patients. As the German short form of a

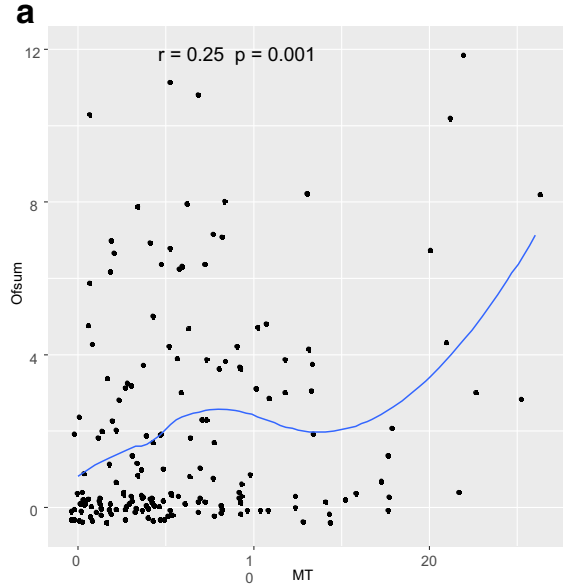

b

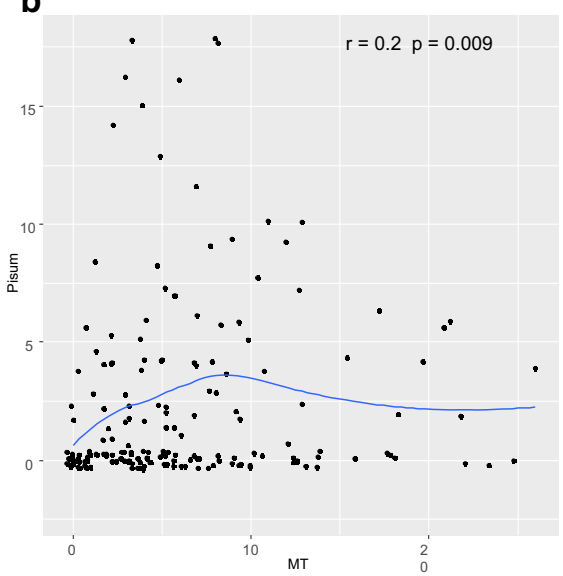

C

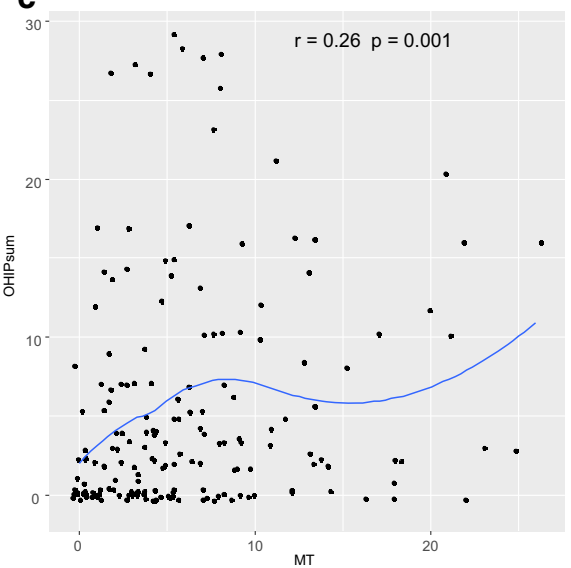

Fig. 1 Scatterplot and correlation between the number of missing teeth (M-T) and the OHIP G14 dimensions oral function (a), psychosocial impact (b) and the OHIP G14 sum score (c) 
Table 3 Associations between dental treatment need as well as dental behaviour with the OHIP G14 sum score, oral function and psychosocial impact; values are shown as the mean value \pm standard deviation [median]

\begin{tabular}{|c|c|c|c|c|}
\hline Factor of interest & & Oral function & Psychosocial impact & Sum score \\
\hline \multirow[t]{3}{*}{ Dental treatment need } & Yes $(n=34)$ & $2.1 \pm 2.9[0]$ & $2.8 \pm 4.2[0.5]$ & $6.0 \pm 8.0[2.5]$ \\
\hline & No $(n=142)$ & $1.9 \pm 2.7[0]$ & $2.3 \pm 4.0[0]$ & $5.2 \pm 6.9[2.5]$ \\
\hline & $p$ value & 0.995 & 0.400 & 0.617 \\
\hline \multirow[t]{3}{*}{ Importance of healthy teeth } & $\operatorname{High}(n=131)$ & $2.1 \pm 2.9[1]$ & $2.6 \pm 4.2[0]$ & $5.9 \pm 7.5[3]$ \\
\hline & Low $(n=45)$ & $1.4 \pm 2.2[0]$ & $1.8 \pm 3.2[0]$ & $3.8 \pm 5.6[2]$ \\
\hline & $p$ value & 0.198 & 0.243 & 0.061 \\
\hline \multirow[t]{3}{*}{ Dental rehabilitation since RA diagnosis } & Yes $(n=153)$ & $2.0 \pm 2.9[0]$ & $2.4 \pm 4.0[0]$ & $5.5 \pm 7.2[3]$ \\
\hline & No $(n=23)$ & $1.5 \pm 2.0[1]$ & $2.2 \pm 4.2[0]$ & $4.8 \pm 6.5[2]$ \\
\hline & $p$ value & 0.802 & 0.663 & 0.987 \\
\hline \multirow[t]{5}{*}{ Time since last dental visit } & $0-3$ months $(n=78)$ & $2.3 \pm 3.0[1]$ & $3.1 \pm 4.6[0]$ & $6.4 \pm 8.0[3]$ \\
\hline & $3-6$ months $(n=45)$ & $2.2 \pm 2.9[1]$ & $2.6 \pm 3.9[0]$ & $5.9 \pm 7.2[3]$ \\
\hline & $6-12$ months $(n=41)$ & $1.2 \pm 1.9[0]$ & $1.1 \pm 2.9[0]$ & $3.2 \pm 5.2[2]$ \\
\hline & $>12$ months $(n=11)$ & $1.2 \pm 2.6[0]$ & $2.2 \pm 2.1[2]$ & $4.3 \pm 5.5[2]$ \\
\hline & $\mathrm{p}$ value & 0.185 & 0.024 & 0.200 \\
\hline \multirow[t]{6}{*}{ Reason for last dental visit } & Control $(n=70)$ & $1.7 \pm 2.6[0]$ & $1.8 \pm 3.3[0]$ & $4.3 \pm 6.1[2]$ \\
\hline & Ongoing treatment $(n=48)$ & $2.3 \pm 3.1[1]$ & $3.0 \pm 4.8[0]$ & $6.2 \pm 7.7[3]$ \\
\hline & Tooth cleaning $(n=31)$ & $1.5 \pm 2.3[0]$ & $1.9 \pm 3.8[0]$ & $4.5 \pm 7.0[2]$ \\
\hline & Pain $(n=21)$ & $2.2 \pm 2.9[1]$ & $3.8 \pm 4.2[2]$ & $8.0 \pm 8.4[4]$ \\
\hline & Others $(n=6)$ & $2.8 \pm 3.9[1.5]$ & $2.2 \pm 3.4[0]$ & $6.2 \pm 8.7[1.5]$ \\
\hline & $p$ value & 0.683 & 0.036 & 0.182 \\
\hline
\end{tabular}

Significant results $(p<0.05)$ are highlighted in bold

the OHIP only includes 14 questions, in which "orofacial appearance" and "oral pain" are represented by only one question, only the other two dimensions were analysed explicitly. In contrast to the OHIP sum score, no reference values for these scores are available yet. However, one previous study that investigated a cohort of patients undergoing haemodialysis found the mean value for oral function to be 1.7 and that of psychosocial impact to be 2.1, which is comparable to those in the RA group in the current study [7]. This can lead to the presumption that the effects of these dimensions are comparable between different patients with severe general (chronic) diseases. However, more comparable literature is needed to draw conclusions regarding this issue.

While previous studies have shown impaired OHRQoL in individuals with rheumatic disease to be independent of oral health conditions $[8,9]$, the current study found a significant correlation between the number of missing teeth and the OHIP G14 score. Moreover, this result was present in the results on both oral function and psychosocial impact. RA is potentially associated with tooth loss, resulting in an increased number of missing teeth [13-15]. A large number of missing teeth is associated with reduced OHRQoL in generally healthy participants $[29,30]$. Accordingly, this correlation seems plausible. This result is of potential clinical relevance because prosthetic rehabilitation can sustainably improve OHRQoL [31]. Moreover, periodontal diseases can affect OHRQoL [6].
Considering the bidirectional relationship between periodontitis and rheumatoid arthritis [13, 14], the exceptionally high periodontal treatment need in the RA cohort within the current study is comprehensible. Because $97 \%$ of the patients needed periodontal treatment, it was not possible to investigate this issue regarding OHRQoL, but an impact is plausible. Additionally, the time since the last dental visit and its reason were associated with the psychosocial impact dimension of the OHIP G14. It is conceivable that patients who consulted their dentist within the 3 months before the examination in particular did this because they experienced pain. This is one possible explanation; however, these associations cannot be compared to any existing literature.

Another major finding was the correlation between RAspecific parameters and OHRQoL. A previous study investigating patients with ankylosing spondylitis found disease activity and specific complaints to be associated with a worse OHIP G14 sum score [8]. In the current study, disease activity was especially correlated with psychosocial impact. This result is in line with that in a recent study showing a moderate reduction in OHRQoL to be related to a high general health deficit in RA patients [10]. It is known that disease activity, reflected by the DAS28-ESR, is an independent predictor of health-related quality of life in RA patients [32]. As a part of health-related quality of life [4], OHRQoL seems to be affected by disease activity, especially that regarding psychosocial 
Table 4 Correlation between the OHIP G14 sum score and the dimensions oral function and psychosocial impact and age well as the RA-related parameters and association between gender and OHIP G4 scores

\begin{tabular}{lllll}
\hline Parameter & & $\begin{array}{l}\text { Oral } \\
\text { function }\end{array}$ & $\begin{array}{l}\text { Psychosocial } \\
\text { impact }\end{array}$ & $\begin{array}{l}\text { OHIP G14 sum } \\
\text { score }\end{array}$ \\
\hline Gender (OHIP G14 mv \pm sd & Male & $2.2 \pm 3.2[0]$ & $2.9 \pm 4.4[0]$ & $6.1 \pm 8.9[2]$ \\
[median]) & Female & $1.9 \pm 2.7[0]$ & $2.3 \pm 2.9[0]$ & $5.2 \pm 6.7[3]$ \\
& $p$ value & 0.927 & 0.527 & 0.88 \\
Age & Spearman & 0.02 & -0.19 & -0.10 \\
Disease duration in months & $p$ value & 0.822 & 0.012 & 0.198 \\
& Spearman & 0.04 & -0.06 & -0.02 \\
DAS28-ESR & $p$ value & 0.647 & 0.481 & 0.801 \\
Number of swollen joints & Spearman & 0.11 & 0.19 & 0.16 \\
& $p$ value & 0.162 & 0.012 & 0.041 \\
Number of painful joints & Spearman & 0.07 & 0.14 & 0.10 \\
& $p$ value & 0.405 & 0.089 & 0.201 \\
Morning stiffness in min & Spearman & 0.08 & 0.12 & 0.07 \\
& $p$ value & 0.297 & 0.148 & 0.404 \\
& Spearman & 0.19 & 0.18 & 0.22 \\
& $p$ value & 0.019 & 0.024 & 0.006 \\
\hline
\end{tabular}

DAS28-ESR disease activity score, significant results $(p<0.05)$ are highlighted in bold impact. Furthermore, the duration of morning stiffness was correlated with a worse OHIP G14 sum score, including both oral function and psychosocial impact. Similar to disease activity, morning stiffness is associated with worse healthrelated quality of life [33]. Moreover, the presence of prolonged morning stiffness affects patients' ability to perform daily routine tasks [34]. Accordingly, the functional aspect, which potentially affects food intake, especially in the morning, might influence aspects such as "taste worsened", the "necessity of interrupting meals" and "uncomfortable to eat" in the affected patients. As this is displayed in the dimension of oral function, the correlation with morning stiffness seems plausible. As potential confounders, age and disease duration can be discussed, because these parameters might be related to disease progress and severity and thus quality of life. While a negative correlation of age with the dimension psychosocial impact was found, the disease duration did not affect the OHRQoL findings. These results argue against the hypothesis that progress in severity of both oral health problems and rheumatoid arthritis with age and disease duration of the RA patients would lead to an increased affection of OHRQoL. Altogether, difficulties in self-care experienced by patients with RA, especially those with severe or longstanding forms of the disease, can be seen as a psychological burden with a potential effect on individual oral health perception. Therefore, disease activity, functional disability, depression and anxiety are important factors affecting patients' self-care and quality of life [35]. This might lead to a continuous reduction in general quality of life as well as OHRQoL in RA patients. Therefore, a multidisciplinary approach that provides personalized care of the patients, focusing on the specific difficulties experienced by individual RA patients, is needed [36]. This must be implemented in dental care settings accordingly.

Regardless of the fact that the detected correlations were statistically significant, they only reported weak relationships. According to the definition by Cohen [27], the effect size of the significant correlations between 0.16 and 0.26 must be interpreted as small. This result might suggest only a slight effect of the examined parameters on the OHRQoL of the RA patients in the current study. However, the reduction in OHRQoL in general was rather minor, which might influence the scale of possible effects of RA-specific parameters on oral health. Therefore, it must be considered that the presented results are purely correlated and that they do not necessarily reflect cause-effect findings.

Strengths and limitations: To the authors' knowledge, this study has the largest cohort of patients suffering RA in which OHRQoL effects on oral health and disease-specific parameters have been investigated and is the first study investigating the different dimensions of OHRQoL in RA patients. The applied questionnaire is valid, and the clinical examinations were performed by calibrated dentists under standardized conditions. Although the OHIP G14 questionnaire is a valid instrument, it does not mandatorily reflect the physical impact of oral health and only reflects the individual perception of the patients. Therefore, a clear distinction between the impact of oral health and rheumatoid arthritis on OHRQoL in RA patients is not possible. It remains unclear whether the psychological burden of the underlying factors of RA affects patients' perception of their oral health and thus their oral behaviour. Furthermore, the cross-sectional study design limits the 
possibility of drawing causative conclusions. Thereby, the gender distribution is conspicuous, showing more than three quarters of participants to be female. However, the analysis of potential associations between gender and OHIP G14 scores did not reveal a clinically relevant or statistically significant result. Moreover, it is well known that more female patients suffer from RA [37]. Accordingly, this gender distribution is a limitation indeed but is a general aspect within cross-sectional examinations of RA patients. The absence of a control group might be a limitation in comparing the OHIP G14 values. On the one hand, reference values for the healthy general population are available, and on the other hand, a comparison of disease-specific factors may be impossible regardless. Furthermore, RA patients are a heterogeneous group who consume different medications, which is a factor that has not been considered. However, immunosuppressive medication might be a major influential factor of oral health, disease activity and thus OHRQoL. In future studies, medication should be examined as an influential factor of OHRQoL. Moreover, the correlations assessed are slight to moderate correlations and show that there is not one major influential factor within the assessed parameters. This result underlines the complexity of the patient group and OHRQoL. In this respect, xerostomia may also be a major factor affecting OHRQoL in RA patients that may also be of relevance [17], which was not considered in the current examination. Nevertheless, the current study provides new insights regarding the OHRQoL of RA patients with potential clinical relevance.

\section{Conclusion}

The number of missing teeth, disease activity and presence of morning stiffness are correlated with worse OHRQoL of patients suffering from RA. Accordingly, periodontal support to avoid tooth loss and prosthetic rehabilitation for patients with missing teeth might increase OHRQoL in these patients. Psychosocial and disease-specific parameters must be considered in the multidisciplinary dental care of RA patients.

Funding Information Open Access funding provided by Projekt DEAL.

\section{Compliance with ethical standards}

Conflict of interest Gerhard Schmalz declares that he has no conflict of interest. Stefan Noack declares that he has no conflict of interest. Susann Patschan declares that she has no conflict of interest. Daniel Patschan declares that he has no conflict of interest. Gerhard A. Müller declares that he has no conflict of interest. Annegret Rupprecht declares that she has no conflict of interest. Jan Schmickler declares that he has no conflict of interest. Rainer Haak declares that he has no conflict of interest. Dirk Ziebolz declares that he has no conflict of interest.

Ethical approval All procedures performed in the current study were in accordance with the ethical standards of the institutional ethics committee (application No. 14/2/13) and with the 1964 Helsinki declaration and its later amendments or comparable ethical standards.

Informed consent Informed consent was obtained from all individual participants included in the study.

Open Access This article is licensed under a Creative Commons Attribution 4.0 International License, which permits use, sharing, adaptation, distribution and reproduction in any medium or format, as long as you give appropriate credit to the original author(s) and the source, provide a link to the Creative Commons licence, and indicate if changes were made. The images or other third party material in this article are included in the article's Creative Commons licence, unless indicated otherwise in a credit line to the material. If material is not included in the article's Creative Commons licence and your intended use is not permitted by statutory regulation or exceeds the permitted use, you will need to obtain permission directly from the copyright holder. To view a copy of this licence, visit http://creativecommons.org/licenses/by/4.0/.

\section{References}

1. Ferro F, Elefante E, Luciano N, Talarico R, Todoerti M (2017) One year in review 2017: novelties in the treatment of rheumatoid arthritis. Clin Exp Rheumatol 35:721-734

2. Katz P (2017) Causes and consequences of fatigue in rheumatoid arthritis. Curr Opin Rheumatol 29:269-276

3. Pu D, Luo J, Wang Y, Ju B, Lv X, Fan P, He L (2018) Prevalence of depression and anxiety in rheumatoid arthritis patients and their associations with serum vitamin D level. Clin Rheumatol 37:179184

4. Reissmann DR, John MT, Schierz O, Kriston L, Hinz A (2013) Association between perceived oral and general health. J Dent 41: 581-589

5. Visscher CM, Lobbezoo F, Schuller AA (2014) Dental status and oral health-related quality of life. A population-based study. J Oral Rehabil 41:416-422

6. Buset SL, Walter C, Friedmann A, Weiger R, Borgnakke WS, Zitzmann NU (2016) Are periodontal diseases really silent? A systematic review of their effect on quality of life. J Clin Periodontol 43:333-344

7. Schmalz G, Dietl M, Vasko R, Müller GA, Rothermund L, Keller F et al (2018) Dialysis vintage time has the strongest correlation to psychosocial pattern of oral health-related quality of life - a multicentre cross-sectional study. Med Oral Patol Oral Cir Bucal 23:e698-e706

8. Schmalz G, Douglas D, Douglas D, Patschan S, Patschan D, Müller GA, Haak R, Schmickler J, Ziebolz D (2018) Oral health-related quality of life is associated with disease specific parameters in patients with ankylosing spondylitis. Clin Oral Investig 22:28892896

9. Mühlberg S, Jäger J, Krohn-Grimberghe B, Patschan S, Mausberg RF, Schmalz G, Haak R, Ziebolz D (2017) Oral health-related quality of life depending on oral health in patients with rheumatoid arthritis. Clin Oral Investig 21:2661-2670

10. Tristiu R, Vesa S, Dumitru RB, Arweiler NB, Cosgarea RM, Lascu L, Rednic S, Eick S, Sculean A, Cosgarea R (2018) Association of oral-health related quality of life and general health assessment in patients with rheumatoid arthritis. Oral Health Prev Dent 16:271280

11. Blaizot A, Monsarrat P, Constantin A, Vergnes JN, de Grado GF, Nabet C, Cantagrel A, Sixou M (2013) Oral health-related quality 
of life among outpatients with rheumatoid arthritis. Int Dent J 63: $145-153$

12. Ahola K, Saarinen A, Kuuliala A, Leirisalo-Repo M, Murtomaa H, Meurman JH (2015) Impact of rheumatic diseases on oral health and quality of life. Oral Dis 21:342-348

13. Potempa J, Mydel P, Koziel J (2017) The case for periodontitis in the pathogenesis of rheumatoid arthritis. Nat Rev Rheumatol 13: 606-620

14. Kaur S, White S, Bartold PM (2013) Periodontal disease and rheumatoid arthritis: a systematic review. J Dent Res 92:399-408

15. de Pablo P, Dietrich T, McAlindon TE (2008) Association of periodontal disease and tooth loss with rheumatoid arthritis in the US population. J Rheumatol 35:70-76

16. Schmickler J, Rupprecht A, Patschan S, Patschan D, Müller GA, Haak R, Mausberg RF, Schmalz G, Kottmann T, Ziebolz D (2017) Cross-sectional evaluation of periodontal status and microbiologic and rheumatoid parameters in a large cohort of patients with rheumatoid arthritis. J Periodontol 88:368-379

17. Chamani G, Shakibi MR, Zarei MR, Rad M, Pouyafard A, Parhizkar A, Mansoori M (2017) Assessment of relationship between xerostomia and oral health-related quality of life in patients with rheumatoid arthritis. Oral Dis 23:1162-1167

18. Aletaha D, Neogi T, Silman AJ, Funovits J, Felson DT, Bingham CO (2010) Rheumatoid arthritis classification criteria: an American College of Rheumatology/European League against rheumatism collaborative initiative. Ann Rheum Dis 69:1580-1588

19. Barczyńska TA, Dura M, Blumfield E et al (2015) DAS28 score vs. ultrasound examination for assessment of rheumatoid arthritis disease activity: comparison and discussion of pros and cons. Reumatologia 53:213-218

20. Slade GD, Spencer AJ (1994) Development and evaluation of the oral health impact profile. Community Dent Health 11:3-11

21. John MT, Patrick DL, Slade GD (2002) The German version of the oral health impact profile - translation and psychometric properties. Eur J Oral Sci 110:425-433

22. Reissmann DR, Krautz M, Schierz O, John MT, Rudolph M, Szentpétery A (2008) Assessment of clinically significant changes in oral health. German Dent J 63:668-680

23. John MT, Rener-Sitar K, Baba K, Čelebić A, Larsson P, Szabo G, Norton WE, Reissmann DR (2016) Patterns of impaired oral healthrelated quality of life dimensions. J Oral Rehabil 43:519-527

24. Brennan DS, Spencer AJ (2004) Dimensions of oral health related quality of life measured by EQ-5D+ and OHIP-14. Health Qual Life Outcomes 2:35

25. World Health Organization (WHO) Geneva: Oral Health Surveys 1997; Basic Methods. 4th Edition
26. Diamanti-Kipioti A, Papapanou TN, Moraitaki-Zamitsai A, Lindhe J, Mitsis F (1993) Comparative estimation of periodontal conditions by means of different index systems. J Clin Periodontol 20:656

27. Cohen J (1988) Statistical power analysis for the behavioral sciences, 2nd edn. Lawrence Earlbaum Associates, Hillsdale

28. John MT, Micheelis W, Biffar R (2004) Reference values in oral health-related quality of life for the abbreviated version of the oral health impact profile. Swiss Dent J 114:784-791

29. Gerritsen AE, Allen PF, Witter DJ, Bronkhorst EM, Creugers NHJ (2010) Tooth loss and oral health-related quality of life: a systematic review and meta-analysis. Health Qual Life Outcomes 8:126

30. Hultin M, Davidson T, Gynther G, Helgesson G, Jemt T, Lekholm U, Nilner K, Nordenram G, Norlund A, Rohlin M, SunnegardhGronberg K, Tranaeus S (2012) Oral rehabilitation of tooth loss: a systematic review of quantitative studies of OHRQoL. Int J Prosthodont 25:543-552

31. Aarabi G, John MT, Schierz O, Heydecke G, Reissmann DR (2015) The course of prosthodontic patients' oral health-related quality of life over a period of 2 years. J Dent 43:261-268

32. González-Gamboa LM, Barocio-Ramírez AK, Rocha-Muñoz AD, de Santos-Ávila F, Meda-Lara RM, González-López L, GámezNava JI, Gómez-Bañuelos E, Chavarria-Avila E, Durán-Barragán S, Navarro-Hernández RE, Pizano-Martínez OE, Nuñez-Atahualpa L, Vázquez-del Mercado M (2016) Disease activity score on 28 joints and polypharmacy are independent predictors for healthrelated quality of life evaluated by INCAVISA in patients with rheumatoid arthritis. J Clin Rheumatol 22:399-404

33. Iqbal I, Dasgupta B, Taylor P, Heron L, Pilling C (2012) Elicitation of health state utilities associated with differing durations of morning stiffness in rheumatoid arthritis. J Med Econ 15:1192-2000

34. da Silva JA, Phillips S, Buttgereit F (2011) Impact of impaired morning function on the lives and well-being of patients with rheumatoid arthritis. Scand J Rheumatol Suppl 125:6-11

35. Katchamart W, Narongroeknawin P, Chanapai W, Thaweeratthakul P (2019) Health-related quality of life in patients with rheumatoid arthritis. BMC Rheumatol 3:34

36. Lempp H, Scott D, Kingsley G (2006) The personal impact of rheumatoid arthritis on patients' identity: a qualitative study. Chronic Illn 2:109-120

37. Scott DL, Wolfe F, Huizinga TW (2010) Rheumatoid arthritis. Lancet 376:1094-1108

Publisher's note Springer Nature remains neutral with regard to jurisdictional claims in published maps and institutional affiliations. 